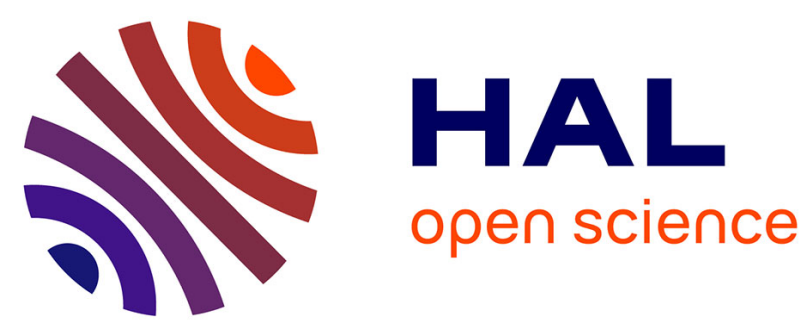

\title{
Pseudorotaxanes of Cyclodextrin and Diglycidyl Ether of Bisphenol A as Precursors of New Intramolecularly Reinforced Epoxy-based Thermosets
}

Gustavo González-Gaitano, Javier González-Benito

\section{- To cite this version:}

Gustavo González-Gaitano, Javier González-Benito. Pseudorotaxanes of Cyclodextrin and Diglycidyl Ether of Bisphenol A as Precursors of New Intramolecularly Reinforced Epoxy-based Thermosets. Supramolecular Chemistry, 2008, 20 (03), pp.335-344. 10.1080/10610270701305401 . hal-00513511

\author{
HAL Id: hal-00513511 \\ https://hal.science/hal-00513511
}

Submitted on 1 Sep 2010

HAL is a multi-disciplinary open access archive for the deposit and dissemination of scientific research documents, whether they are published or not. The documents may come from teaching and research institutions in France or abroad, or from public or private research centers.
L'archive ouverte pluridisciplinaire $\mathbf{H A L}$, est destinée au dépôt et à la diffusion de documents scientifiques de niveau recherche, publiés ou non, émanant des établissements d'enseignement et de recherche français ou étrangers, des laboratoires publics ou privés. 


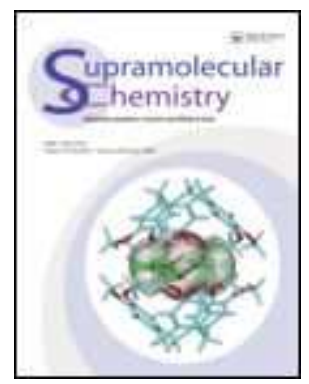

\section{Pseudorotaxanes of Cyclodextrin and Diglycidyl Ether of Bisphenol A as Precursors of New Intramolecularly Reinforced Epoxy-based Thermosets}

\begin{tabular}{|r|l|}
\hline Journal: & Supramolecular Chemistry \\
\hline Manuscript ID: & GSCH-2006-0124.R3 \\
\hline Manuscript Type: & Full Paper \\
\hline $\begin{array}{r}\text { Date Submitted by the } \\
\text { Author: }\end{array}$ & $27-F e b-2007$ \\
\hline Keywords: & $\begin{array}{l}\text { cyclodextrin, DGEBA, ROESY, semi-rigid docking, fluorescence } \\
\text { Ingeniería de Materiales e Ingeniería Química }\end{array}$ \\
\hline \multicolumn{2}{|r}{} \\
\hline
\end{tabular}

\section{今) ScholarONE" \\ Manuscript Central}




\title{
Pseudorotaxanes of Cyclodextrin and Diglycidyl Ether of Bisphenol A as Precursors of New Intramolecularly Reinforced Epoxy-based
}

\section{Thermosets}

\author{
Gustavo González-Gaitano* and Javier González-Benito ${ }^{\dagger}$
}

* Corresponding author: Dpto. de Química y Edafología. Universidad de Navarra.

31080. Pamplona. Navarra. SPAIN. E-mail: gaitano@unav.es

$†$ Dpto. Ciencia e Ingeniería de Materiales e Ingeniería Química. Universidad Carlos III de Madrid. Avda. Universidad 30, 28911 Leganés. Madrid. SPAIN. E-mail: javid@ing.uc3m.es 
Abstract

As a preliminary work in the search of potential monomers for new intramolecularly reinforced epoxy-based materials, this investigation has been aimed at the synthesis and the physico-chemical characterisation of the monomers formed by complexation between $\beta$ - and $\gamma$-cyclodextrin (CD) and diglycidyl ether of bisphenol $\mathrm{A}$ (DGEBA). Results from steady-state fluorescence suggest that, even at high temperature, the DGEBA forms very stable complexes with both macrocycles (particularly with the $\beta-\mathrm{CD}$ ) in aqueous solution. Regardless the $\mathrm{CD}$ and according to the interproton distances obtained from the ROESY spectrum when compared with the simulated ones by semi-rigid docking, the oxirane ring of the DGEBA monomer can be found outside the cavity, while the bisphenol moiety firmly remains attached and buried into the CD. The stability of the adduct and the lack of steric hindrance at the epoxide functional points, make the complex very interesting for the synthesis of crosslinked epoxy based polymers, in which the bisphenol part would be covered and therefore protected by the $\mathrm{CD}$. The semi-rigid docking scheme applied to this host-guest system reveals as a useful tool for the search of conformers that fit the experimental distances obtained by NMR, although its utility for the estimation of the free energies of binding is still limited. 


\section{INTRODUCTION}

In the last three decades, the research in epoxy based thermoset polymers has been mainly focused on the enhancement of their toughness by incorporating elastomers and/or thermoplastic polymers ${ }^{1,2}$. In most of the cases, different issues related with miscibility and the effect of the toughness modifier in the curing process of the thermoset $^{3,4}$ have been studied since this knowledge is necessary to understand the performance of the final materials. The most important limitation of using elastomermodified epoxies is that the toughness enhancement only can be obtained reducing the range of applicability, for example, at high temperatures in applications for which the mechanical demands are very high. Due to this, thermoplastics with high glass transition temperature have been proposed as an alternative for many applications ${ }^{5}$. A way of attaining improvements in the material, might be to work on the material at a molecular scale, reinforcing the stability of the functional groups and bonds by the incorporation of other molecules, which could provide higher structural rigidity and chemical stability. A possible approach might be to cover several parts of the chains in the thermosetting by means of supramolecular encapsulation with a macrocycle, which would imply, as a first stage, the synthesis of new "armoured" epoxy monomers. This new thermoset structure might affect not only the mechanical resistance, but also the endurance to thermal degradation..

Good candidates for the described systems as molecular encapsulants might be cyclodextrins (CDs). One of the most important features of these macrocycles is the possibility of forming inclusion complexes with a wide variety of guests ${ }^{6}$. In the case of a linear guest, the resulting complex is referred as a pseudorotaxane, i.e., a stable bimolecular system formed by a linear molecule that is threading the $\mathrm{CD}^{7,8}$. Recently, special interest have been showed in the so-called "polyrotaxanes" in which a polymer 
threads several cyclodextrin rings generating rigid molecular structures in a necklace fashion ${ }^{9}$. These new supramolecular associations have interest because of their potential uses for the creation of new molecular materials ${ }^{10,11}$. However, to our knowledge, no works have been published in which a pseudorotaxane was an intrinsic part of an epoxy-based thermoset. The study of these new intramolecularly reinforced thermoset polymers is crucial to corroborate their potential applications.

In this frame, the aim of this work has been to produce and characterise physicochemically two complexes formed between cyclodextrins and diglycidyl ether of bisphenol A, CD/DGEBA ( $\beta$-CD/DGEBA and $\gamma$-CD/DGEBA) as potential monomers for new intramolecularly reinforced epoxy-based materials. The study focuses on the stability of these new complexes and their 3D molecular structure. The stoichiometry, binding constants and thermodynamic parameters have been evaluated by steady-state florescence using the intrinsic fluorescence of the DGEBA ${ }^{12}$. The 3D molecular structure of the complex, necessary for the evaluation of the viability of the monomer for its subsequent polymerisation, has been deduced by using jointly bidimensional ROESY (Rotating-frame Overhauser Enhancement Spectroscopy) and automated docking molecular modelling procedures. The validity of the automated docking for CD based host-guest systems, not frequently used but of potential interest, due to its simplicity of calculation, is also discussed.

\section{MATERIALS AND METHODS}

\section{Chemicals}

$\beta$-Cyclodextrin ( $\beta$-CD) (Figure 1, top) was manufactured by Roquette (10\% water content, $99.8 \%$ purity) and $\gamma-\mathrm{CD}$ (Figure 1, top) by Wacker (7.9\% water content, 
99.5\% purity). Poly (Bisphenol A-co-epichlorohydrin) glycidyl end-capped (commonly named Di-Glycidyl Ether of Bisphenol A, DGEBA, Figure 1 bottom) was obtained from Sigma-Aldrich $\left(\mathrm{M}_{\mathrm{n}}=348 \mathrm{~g} \mathrm{~mol}^{-1}, 99 \% \text { purity }\right)^{\dagger}$. The solutions for fluorescence and absorption experiments were prepared with type I-grade water. For the liquid NMR experiments, deuterated water $\left(\mathrm{D}_{2} \mathrm{O}\right)$ was used as the solvent (Aldrich, $99.9 \%$ deuterium degree).

\section{UV absorption and fluorescence spectroscopy}

For recording the UV spectra a HP 8452A diode array spectrophotometer was used, keeping fixed the temperature at $25.0 \pm 0.1{ }^{\circ} \mathrm{C}$, in $1.000 \mathrm{~cm}$-pathlength quartz cells.

Steady-state fluorescence measurements were performed using a Perkin-Elmer LS-50B spectrofluorimeter. An $1.000 \mathrm{~cm}$-pathlength quartz cell was employed, keeping constant the temperature with an external heated circulating bath. Four temperatures were considered: $15,25,35$ and $45^{\circ}$ with an accuracy of $\pm 0.1{ }^{\circ} \mathrm{C}$. The DGEBA concentration was fixed at $1.82 \times 10^{-5} \mathrm{M}$ for the fluorescence titration experiments, while the ratio $\mathrm{CD} / \mathrm{DGEBA}$ was varied by direct addition in the cell of a stock solution containing DGEBA + CD. The excitation wavelength corresponded to the $\lambda_{\max }$ in the absorption spectrum at $273 \mathrm{~nm}$. The scan rate was $300 \mathrm{~nm} / \mathrm{min}$ and the excitation and emission slits were set at spectral bandpasses of 6.0 and $2.5 \mathrm{~nm}$, respectively.

$\dagger$ The DGEBA has a more general formula than the depicted in Figure 1, in which a block of $-[\mathrm{Ph}-$ $\left.\mathrm{C}\left(\mathrm{CH}_{3}\right)_{2}-\mathrm{Ph}-\mathrm{O}-\mathrm{CH}_{2}-\mathrm{CHOH}-\mathrm{CH}_{2} \mathrm{O}\right]_{n}-$ is inserted between the bisphenol and the epoxy residue. However, in our case $n=0.03$, a contribution that can be considered negligible for practical purposes in the subsequent computational and NMR studies. 


\section{NMR experiments}

The samples for the $1 \mathrm{D}{ }^{1} \mathrm{H}$ NMR spectra were prepared in $\mathrm{D}_{2} \mathrm{O}$ by adding solutions of $\beta$ - and $\gamma$-CD to vials containing weighed amounts of DGEBA. The spectra were recorded at $300 \mathrm{~K}$ in a Bruker Avance 400 Ultrashield spectrometer $(9.36 \mathrm{~T})$ by averaging 512 scans. For the 2D ROESY experiments, samples were prepared by adding liquid DGEBA to a solution of either $\beta$ or $\gamma-\mathrm{CD}$ in $\mathrm{D}_{2} \mathrm{O}(4.9 \mathrm{mM}$ and $10 \mathrm{mM}$, respectively). After sonication, the supernatant is recovered and transferred to a NMR tube. The ROESY spectra were recorded at $298 \mathrm{~K}$ with a Bruker Avance AV500 spectrometer $(11.7 \mathrm{~T})$ equipped with an inverse gradient probehead with z-field gradient capability. The pulse sequence used is described in ref. 13. Solvent presaturation was achieved with a power level of $60 \mathrm{~dB}$. The $90^{\circ}{ }^{1} \mathrm{H}$ hard pulse was $31.5 \mu \mathrm{s}$, and the power level for the spin-lock pulse $\gamma_{1} / 2 \pi=7942 \mathrm{~Hz}$. In order to get the best signal-tonoise ratio, different spin-lock mixing times were applied, achieving best results with $600 \mathrm{~ms}$. Forty-eight scans were collected in each experiment, giving a matrix of 2048 $\times 1024$ points, which covered a spectral width of $4496 \mathrm{~Hz}$. The FFT, phasing and baseline correction of the free induction decays (FIDs) was carried out with MestRe-C software $^{14}$. The interproton distances have been calculated from the NOE peaks by the equation $^{15}$

$r_{i j}=r_{r e f}\left(\frac{c_{r e f} a_{r e f}}{c_{i j} a_{i j}}\right)^{1 / 6}$

where $a_{i j}$ is the NOE cross-peak volume and $r_{\text {ref }}$ is a reference distance between two protons yielding a NOE volume, $a_{\text {ref. }}$ The coefficients $c_{i j}$ are introduced to account for 


$$
c_{i j}=\frac{1}{\sin ^{2} \theta_{i} \sin ^{2} \theta_{j}}
$$

and

$$
\tan \theta_{\alpha}=\frac{\gamma B_{1}}{\omega_{\alpha}-\omega_{0}}, \alpha=i \text { or } j
$$

In these expressions, $\omega_{\alpha}-\omega_{0}$ is the difference in $\mathrm{Hz}$ between the chemical shift of the peak and the centre of the spectral window $\left(2352 \mathrm{~Hz}\right.$ in our experiments), and $\gamma \mathrm{B}_{1}$ is the spin-lock power. In the integration of the NOE signals with MestRe-C only positive values were considered.

\section{Computational Studies and Methodology}

The building and structure refining of the host (cyclodextrins) and guest (DGEBA) molecules were performed with Insight II software ${ }^{17}$ on an SGI Octane2 workstation, employing the CVFF forcefield. Different algorithms supplied with the Discover module (steepest descents, conjugate gradients and Newton-Raphson to final refining of the structures) were successively used for the energy minimisation until the root-mean squares of the derivatives were less than $0.0001 \mathrm{kcal} \AA^{-1}$. Afterward, short molecular dynamics (MD) simulations were run at $298 \mathrm{~K}$ and the process of minimisation was repeated to reach a stable conformation.

The DGEBA has been docked to the $\beta$-CD and $\gamma$-CD with Autodock 3.0. ${ }^{18}$ The program uses a semi-rigid docking approach for docking a flexible ligand onto a rigid 
active site. It searches for torsions around the bonds of the ligand (DGEBA) susceptible to rotate keeping fixed the bond lengths and angles. To search for favourable interaction energies between the host and guest, Autodock generates three-dimensional grids, one for each atom type present in the cyclodextrin $(\mathrm{C}, \mathrm{O}, \mathrm{H})$, where each point within the grid stores the potential energy of a probe atom due to all the atoms of the macrocycle. Then, at every point, the pairwise interaction energy between host and guest is derived from 12,6-Lennard-Jones potentials for Van der Waals forces, and Coulomb for electrostatic interactions. In our calculations, grid positions were $0.375 \AA$ apart in a 22.5 $\AA$ cubic box centred at the CD cavity. For the search strategy we used the Monte Carlo simulated annealing technique (SA) implemented in the software with 1024 runs, each one composed of 50 cycles. A cycle is reached when a maximum of 1000 accepted of rejected steps take place, according to a MC decision routine. Partial charges of the molecules for the automated docking were taken from the CVFF forcefield.

The resulting docked structures yield a set of simulated NOEs, according to eqs. $1-3$, by measuring the distance between the protons of the DGEBA and the CD which produce the most intense cross-peaks in the ROESY spectrum. These are compared to the calculated ones through the evaluation of the root-mean-square (rms) of the differences, with the aid of a routine written in the Biosym Command Language (see Results).

\section{RESULTS AND DISCUSSION}

\section{Spectral features and stability of the complexes}

The effects of CD inclusion on the absorption spectrum of a molecule bearing chromophore groups are characterised by peak shifts of the order of a few nm, the 
presence of isosbestic points, and changes in the extinction coefficients. In the case of DGEBA, the absorption spectrum is virtually not altered with the presence of cyclodextrin, neither in the shape nor in the position of the maxima, at 226 and $273 \mathrm{~nm}$. However, when adding either $\beta$-CD or $\gamma$-CD an enhancement in the emission intensity from the DGEBA occurs, together with a slight blue shift of about $3 \mathrm{~nm}$ (Fig. 2). This enhancement of the fluorescence can be used to estimate the association constant. Usually this is carried out recording either the integrated emission or the intensity at a certain wavelength (currently at $\lambda_{\max }$ ) for different $\mathrm{CD}$ concentrations and linearizing the data by the Benesi-Hildebrand approach, or simply fitting them directly by a non-linear least-squares procedure. In a general case, the fluorescence intensity measured at a certain concentration of $\mathrm{CD}$ is

$$
F_{j}=\sum_{i=0} k_{i} c_{i}
$$

where $k_{i}$ is a constant related to the quantum yield of the $i$ th fluorophore. In the absence of $\mathrm{CD}$, the emission is exclusively due to the guest, $F_{0}=k_{0} c_{0}$, so thus

$$
\frac{F_{j}}{F_{0}}=\sum_{i=1} q_{i} c_{i} / c_{0}
$$

where $q_{i}=k_{i} / k_{0}$. The corresponding mass balance and the mass action law connect the concentrations of the components in solution, so the mathematical model depends also on the stoichiometry of the binding. As an alternative approach it is possible to use a wider set of experimental data by taking into account the emission measured at other wavelengths ${ }^{19}$. In this way, a multivariable analysis of the whole set of wavelengths 
under study can be performed, by imposing the condition that the binding constant (or constants) was the same at each wavelength. This method has the advantage of using a wider set of experimental data, what makes the fitting numerically more stable, useful in the study of multiple equilibria, in which the estimation of the binding constants is more difficult. In addition it estimates the complete emission spectrum of the complex, and not only its quantum yield. With this approach, Eq. 5 is rewritten as:

$$
\left(\frac{F}{F_{0}}\right)_{\lambda}=\sum_{i=1} q_{i, \lambda} c_{i} / c_{0}(6)
$$

and the function to be minimised becomes

$$
E=\sum_{\lambda} \sum_{j} w_{\lambda}\left(\left(F_{j} / F_{0, \lambda}\right)^{c a l}-\left(F_{j} / F_{0, \lambda}\right)\right)^{2} \quad(7)
$$

where a weight factor dependent on the wavelength, $w_{\lambda},=\left|F_{\max , \lambda}-F_{0, \lambda}\right|$, is introduced, taken as the absolute value of the difference between the maximum fluorescence reached in the binding at a certain $\lambda$ and the value at zero concentration of CD. For accomplishing the fit, we have used a routine in MATLAB ${ }^{\circledR}$ based on the NewtonRaphson algorithm. The input is a vector containing an initial guess for the binding constant and $q_{i}$, and the output are the estimation of the parameters together with their error bounds, defined as the confidence intervals corresponding to a significance level, $\alpha=0.16$. The wavelength interval used in all cases was (289 to $329 \mathrm{~nm}$ ) was that one for which the changes in intensity were significant. 
The Benesi-Hildebrand plot of the data at $\lambda_{\max }$ (not shown) indicates a 1:1 stoichiometry, so this has been the model used. The results of the fitting with both CDs at different temperatures are collected in Table 1.

It is worth noting that the binding constants at any of the temperatures under study are considerably high with both hosts, considering a monotopic guest (see, for example, the compilations of binding constants in refs. 20 and 21). Especially stable is the complex with the narrower $\beta-C D$, in which the fitting of the DGEBA inside the cavity must be necessarily tighter than with the $\gamma$-CD.

The binding entropy and enthalpy have been obtained from the temperature dependence of the binding constant through the van't Hoff equation $\left(\ln K\right.$ versus $\left.T^{-1}\right)$ by a weighed least-squares method (Table 1). It is assumed that the thermodynamic parameters of the inclusion remain invariable within the interval of temperatures used $\left(15\right.$ to $\left.45^{\circ} \mathrm{C}\right)$. For both $\mathrm{CDs}$, the absolute value of the enthalpy of complexation is high, compared to other aromatic guests, and the entropy is negative, yielding the $\beta$-CD the most exothermic binding. Taking into account that the bisphenol moiety of the DGEBA is rather bulky, all the water molecules inside the CD must be expelled, and also the DGEBA (or its part included into the cavity) must completely lose its hydration shell. Since the only difference between these complexes is the size of the host cavity, it seems clear that the narrower $\beta$-CD must fit better the DGEBA by establishing more intense van der Waals interactions, yielding therefore a higher enthalpy of inclusion. As for the negative entropy, it is necessary to describe the different contributions involved. On the one hand, the loss in the degrees of freedom of the guest related to the torsions of the aromatic block represents a negative change in entropy; on the other hand, the expelled water of the cavity and the hydration shell of the part of the included DGEBA increases the disorder, which involves a positive contribution. The lower absolute value 
of $\Delta S$ for the $\gamma-\mathrm{CD}$, having a larger cavity in which the DGEBA must fit loosely, seems to indicate that is the torsional contribution the term that rules the change in entropy of the process. With any of the CDs, negative $\Delta H$ and $\Delta S$ account for the production of a very stable complex. This is a paramount aspect in order to prepare and use the adduct as a stable monomer in a polymerisation for obtaining any kind of self-reinforced epoxy polymer.

\section{Structure of the complexes}

When a $\mathrm{D}_{2} \mathrm{O}$ solution of $\beta$ - or $\gamma-\mathrm{CD}$ is mixed and stirred in the presence of an excess of DGEBA and the supernatant is recovered, the 1H NMR spectrum displays some significant changes, which reveal that the dissolved guest has been complexed (Fig. 3). Thus, the inner protons of the $\beta-\mathrm{CD}, \mathrm{H} 3(3.85 \mathrm{ppm})$ and H5 (3.74 ppm) shift upfield, ca. -0.010 and -0.015 ppm, respectively (the H5 signal partially overlaps to that of the H6 protons), whereas no change is perceived in the outer protons of the $\mathrm{CD}, \mathrm{H} 1$, $\mathrm{H} 2$ and H4. In spite of the high value of the binding constants, the upfield shifts in the resonances of the $\beta-\mathrm{CD}$ are rather small. In these experiments, the $\mathrm{CD}$ is in substantial excess with respect to the DGEBA. Since the shifts in their signals are an average of the $\mathrm{CD}$ in its free and bound form, they must change to a lesser extent upon complexation. In the case of the $\gamma-\mathrm{CD}$, the lower binding constant (one order of magnitude) adds to the mentioned effect making the changes virtually undetectable, even though the equilibrium is practically shifted to the complex. More revealing is the effect on the protons of the DGEBA. The aromatic protons appear as two doublets centred at 6.846 (Ha) and $7.170 \mathrm{ppm}(\mathrm{Hb})$, that, in the presence of $\beta-\mathrm{CD}$ shift upfield to 6.783 and 7.122 ppm, respectively. In addition to this, the six equivalent protons of the two methyls 
attached to the central $\mathrm{C}$ are deshielded, showing a shift from 1.525 to $1.631 \mathrm{ppm}$. No changes are detected upon complexation either in the epoxy protons $\mathrm{CH}_{2} \mathrm{OCH}$ or in those of the adjacent $\mathrm{CH}_{2}$ group. These evidences suggest the penetration of the bisphenol nucleus inside the CD cavity, whereas the epoxy wings must remain outside. The low solubility in water of the DGEBA precludes a quantitative monitoring of the chemical shift versus the concentration of added host or guest, which would permit us to estimate the association constant by NMR titration in order to confirm the results obtained by fluorescence.

Regarding the closeness between protons of the host and guest upon the inclusion, the ROESY spectrum (Fig. 4) contains more information than the provided by the $1 \mathrm{D}$ spectra (Fig. 3). The inspection of this $2 \mathrm{D}$ spectrum reveals intense crosspeaks between the aromatic protons of the DGEBA and those of the cavity (H3, H5). Also, an intense NOE rises between the methyl group and both CD protons, although less intense with the H5. The relative volumes of the most important crosspeaks have been collected in Table 2. No correlation is detected between the glycidyl tails and any of the $\beta-C D$ protons, what indicates that the side wings of the molecule are placed outside the cavity, whereas the bisphenol nucleus is deeply buried into the CD. This also agrees with the fluorescence behaviour of the complex, because such changes in the emission intensity must necessarily involve the aromatic part of the guest. Unfortunately, the ROESY spectrum for the $\gamma$-CD did not produce appreciable crosspeaks, which might have allowed us to make subsequent calculations. This is due to the concomitant effect of the lower binding constant for this macrocycle (diminished yield of the reaction) and to the increased distance between protons, which reduces the NOE effect. However, the enhanced fluorescence suggests a similar trend, i. e. the aromatic moiety must be deeply buried inside the CD. 
At this point, automated docking experiments can give us a more precise picture about the structure and energy of the complexes, by extracting the quantitative information contained in the NOEs. Each docked structure obtained according to the SA procedure produces a set of interproton distances that can generate a simulated NOE for each pair of protons, given by Eq. 1 . Due to the seven-fold symmetry of the $\beta$-CD there are 7 equivalent nuclei, and each NOE peak contains the dipolar interactions due to all the set. We define an "effective distance" as an average that accounts for all the equivalent protons giving rise to one NOE signal, $r_{\text {eff, }}$, calculated from the relationship ${ }^{22}$

$$
\frac{1}{r_{e f f}^{6}}=1 / n \sum_{i=1}^{n} \frac{1}{r_{i}^{6}}
$$

being $\mathrm{n}$ the number of equivalent protons in each case. The experimental distances can be extracted from the NOEs provided a reference distance between protons is defined $^{23,24,25}$. In systems with a high symmetry and many equivalent protons, like those considered here, it is useful instead to compare the ratios between distances (or NOEs) ${ }^{26}$. The advantage of this approach is that it does not produce biased results in the geometry if the reference is not well assigned. We have taken as the reference the NOE corresponding to the cross-peak $\mathrm{Ha}-\mathrm{CH}_{3}$. The set NOEs of the 1024 structures generated in the SA calculation are compared to the experimental ones coming from the ROESY by the root mean square deviation defined as:

$$
R M S=\frac{1}{\sqrt{6}} \sqrt{\sum_{i \neq j}^{2} \sum_{j}^{3}\left(a_{i j}^{c a l}-a_{i j}\right)^{2}}
$$


where $i$ stands for either $\mathrm{H} 3$ or $\mathrm{H} 5$, and $j$ for $\mathrm{Ha}, \mathrm{Hb}$, or $\mathrm{CH}_{3}$, and each $a_{i j}$ (experimental or calculated) has been divided by the NOE of reference, $a_{m e t-H a}$.

The structures of the complex have been clustered in Fig. 5, including only the conformers that give the least rms $(<0.35)$, for the sake of clarity. Due to the symmetry of the DGEBA, there is not a preferred affinity of the $\beta$-CD for any end of the molecule. One of the phenyl rings is deeply buried inside the cavity, roughly aligned with the axis of the $\mathrm{CD}$ and close to the narrower rim, whereas the other rather leans close to the secondary border. The two methyl groups are close to the secondary part (i.e. narrow edge) of the macrocycle. It is worth noting that the reactive groups remain unprotected by the $\mathrm{CD}$, outside the cavity, which suggests that there may be a subsequent polymerisation of the included DGEBA.

\section{Calculation of the free energies of binding}

It is possible to estimate the theoretical binding energies with the SA docking. Autodock provides the free energy of binding by calculating the energies of the host, guest and complex in vacuum, and their energies of solvation. The thermodynamic cycle is:

$$
\begin{aligned}
& C D_{\text {vacuo }}+S_{\text {vacuo }} \stackrel{\Delta G_{\text {bind,vacuo }}}{\longrightarrow} C D: S_{\text {vacuo }} \\
& +\mathrm{H}_{2} \mathrm{O} \downarrow \Delta G_{s o l v(C D+S)} \quad+\mathrm{H}_{2} \mathrm{O} \downarrow \Delta G_{s o l v(C D: S)} \\
& C D_{\text {sol }}+S_{\text {sol }} \stackrel{\Delta G_{\text {bind }, \text { sol }}}{\longrightarrow} C D: S_{\text {sol }}
\end{aligned}
$$


The free energy is semiempirically modelled by introducing entropic terms into the molecular mechanics equations. This contribution accounts for the restriction of internal rotors and global rotation and translation, and also for the desolvation upon binding and the hydrophobic effect ${ }^{27}$. From this cycle, the free energy can be estimated as

$$
\Delta G_{b i n d, s o l}=\Delta G_{b i n d, v a c}+\Delta G_{s o l v(C D: S)}-\Delta G_{s o l v(C D+S)}
$$

The free energies of binding are compiled in Table 3, together with the rms with respect to the ROESY data. It can be seen that the average computed energy of binding at $25^{\circ} \mathrm{C},-21 \mathrm{~kJ} \mathrm{~mol}^{-1}$, is considerably smaller than the experimental one (in terms of $K$, $4.7 \cdot 10^{3}$ versus $6.1 \cdot 10^{4}$, at this temperature). Calculations by restraining the torsions in the DGEBA have been performed, yielding poorer $\mathrm{rms}$ and higher energies, as expected, since it represents a less realistic definition of the system. The rigidity of the macrocycle, which is taken for granted in the philosophy of AutoDock for proteins, might be a drastic assumption in the case of a cyclodextrin. The DGEBA must distort in a certain extent the high symmetry of the $\mathrm{CD}$, with implications in the entropy and enthalpy that may bias the results. A possible way of overcoming the drawback of the flexibility of the $\mathrm{CD}$, keeping the simplicity of the semi-rigid docking scheme, could be to develop a more convenient free energy function, calibrated with the copious data available from binding constants of inclusion complexes of cyclodextrins.

It is worth mentioning that the computed binding energies between the conformers with the lowest rms and those with higher rms are not very different, although there is a positive correlation between them. To illustrate this, the rms against the binding energy has been plotted in Fig. 6. According to this plot, there are very stable conformers, which even could reproduce the experimental free energy of binding, 


\section{CONCLUSIONS}

Di-glycidyl ether of bisphenol A (DGEBA) forms very stable complexes with $\beta$ and $\gamma$-CD in aqueous solution, particularly with the narrower macrocycle, even at high temperatures. According to the interproton distances obtained from the ROESY spectrum when compared to the simulated ones by semi-rigid docking SA, with any of the CDs, the reactive part of the monomer (epoxy groups) remains outside the cavity, with the bisphenol moiety firmly attached and buried into the CD. The semi-rigid docking scheme, which accounts for hydration effects on the guest, the host, and the complex, yields computed binding constants much smaller than, but that correlate with, the experimental values. This is most likely due to the implicit assumption in the philosophy of the calculation of considering the binding site (the $\mathrm{CD}$ ) as rigid. The stability of the adduct and the lack of steric hindrance at the functional points, make the complex valuable for the synthesis of crosslinked epoxy based polymers, in which the bisphenol part is covered and protected by the CD.

\section{ACKNOWLEDGEMENTS}

The authors acknowledge financial support from MEC through fund BQU2001-1426C02-02 and fund MAT2004-01347. They also wish to thank G. Tardajos and A. Guerrero for the NMR measurements. 


\section{TABLES}

Table 1. Binding constants $\left(\mathrm{L} \mathrm{mol}^{-1}\right)$ and reaction parameters of the complexes formed between DGEBA and $\beta$ - and $\gamma$-CD.

\begin{tabular}{c|cc}
$\mathbf{T}\left({ }^{\mathbf{o}} \mathbf{C}\right)$ & $\boldsymbol{\beta}-\mathbf{C D}$ & $\boldsymbol{\gamma}$-CD \\
\hline 15 & $(1.45 \pm 0.04) \cdot 10^{5}$ & $(5.3 \pm 0.1) \cdot 10^{3}$ \\
25 & $(6.14 \pm 0.08) \cdot 10^{4}$ & $(4.09 \pm 0.07) \cdot 10^{3}$ \\
35 & $(3.31 \pm 0.07) \cdot 10^{4}$ & $(2.22 \pm 0.04) \cdot 10^{3}$ \\
45 & $(1.90 \pm 0.03) \cdot 10^{4}$ & $(1.64 \pm 0.03) \cdot 10^{3}$ \\
\hline$\Delta G^{298}\left(\mathrm{~kJ} \mathrm{~mol}^{-1}\right)$ & $-27.33 \pm 0.03$ & $-20.62 \pm 0.04$ \\
$\Delta H\left(\mathrm{~kJ} \mathrm{~mol}^{-1}\right)$ & $-49 \pm 3$ & $-32 \pm 4$ \\
$\Delta S\left(\mathrm{~J} \mathrm{~mol}^{-1} \mathrm{~K}^{-1}\right)$ & $-9 \pm 1$ & $-5 \pm 1$
\end{tabular}

Table 2. Relative NOE volumes for intermolecular cross-peaks from the 2D ROESY spectrum of DGEBA $+\beta-C D$.

\begin{tabular}{c|ccc} 
& $\mathrm{Ha}$ & $\mathrm{Hb}$ & $\mathrm{CH}_{3}$ \\
\hline $\mathrm{H} 3$ & 126 & 65 & 59 \\
$\mathrm{H} 5$ & 85 & 45 & 13
\end{tabular}

(Values normalised to the intramolecular NOE Ha- $\mathrm{CH}_{3}=100$ ) 
Table 3. Computed free energy of binding and rms for the conformers giving the best fit to the ROESY data.

\begin{tabular}{c|c} 
RMS & $\Delta G\left(\mathrm{~kJ} \mathrm{~mol}^{-1}\right)$ \\
\hline 0.204 & -20.08 \\
0.252 & -25.10 \\
0.254 & -24.52 \\
0.277 & -20.04 \\
0.299 & -22.30 \\
0.305 & -17.91 \\
0.309 & -21.09 \\
0.311 & -17.95 \\
0.350 & -22.30 \\
0.358 & -20.21 \\
\hline & $<\Delta G>=-21 \pm 2$ \\
\hline
\end{tabular}

\section{FIGURE LEGENDS}

Figure 1. Schematic representation of Cyclodextrin (top) and DGEBA (bottom).

Figure 2. Fluorescence spectra of DGEBA in aqueous solution at different concentrations of a) $\beta-\mathrm{CD}$, and b) $\gamma-\mathrm{CD}$, at $35^{\circ} \mathrm{C}\left([\mathrm{DGEBA}]=1.82 \cdot 10^{-5} \mathrm{M}\right.$ in both cases).

Figure 3. Expansion of the ${ }^{1} \mathrm{H}$ NMR spectra of DGEBA and its complex with $\beta-C D$ in $\mathrm{D}_{2} \mathrm{O}$ (left: $\beta$-CD; right: $\left.\beta-\mathrm{CD}+\mathrm{DGEBA}\right)$

Figure 4. Partial view of the 2D ROESY spectrum for the DGEBA/ $\beta$-CD system

Figure 5. Cluster of the most probable molecular structures of the $\beta$-CD:DGEBA adduct, according to the 2D ROESY data and automated semi-rigid docking simulation (H omitted for the sake of clarity).

Figure 6. Comparison between the rms (root mean square) deviation and the theoretical free energy of binding for the $\beta$-CD:DGEBA complex. 


\section{REFERENCES}

1 Pascault, J.P., Verdu, J., Williams, R.J.J. Thermosetting Polymers, New York: Marcel Dekker, 2002.

2 Verchere, D.; Pascault, J.P.; Saterau, H., Moschiar, S.M.; Riccardi, C.C.; Williams, R.J.J. J. Appl. Polym. Sci. 1991, 43, 701.

3 Williams, R.J.J.; Rozenberg, B.A.; Pascault, J.P. Avd. Polym. Sci. 1997, 128,95.

4 Olmos, D.; González-Benito, J. Colloid Polym. Sci. 2006, 284, 654.

5 González-Benito, J.; Esteban, I. Colloid Polym. Sci. 2005, 283, 559.

6 (a) Szejtli, J. Chem Rev. 1998, 98, 1743, and issues therein. (b) Atwood, J. L.; Davies, J. E. D.; Macnicol, D. D.; Vögtle, F. C. Comprehensive Supramolecular Chemistry (Volume 3: Cyclodextrins); Szejtli, J., Osa, T., Eds; Pergamon: Tarritown, NY, 1996. (c) Duchene, D. New Trends in Cyclodextrins and Derivatives; Editions de Santé: Paris, 1991. (d) Szejtli, J. Cyclodextrins and Their Inclusion Complexes; Kluwer Academic Publishers: Dordrecht, The Netherlands, 1988. (e) Duchene, D. Cyclodextrins and Their Industrial Uses; Editions de Santé: Paris, 1987.

7 Nepogodiev, S.A.; Stoddart, J.F. Chem. Rev. 1998, 98, 1959.

${ }^{8}$ Wenz, G.; Han, B.H., Muller, A. Chem. Rev. 2006, 106, 782.

9 Miyauchi, M.; Hoshino, T.; Yamaguchi, H.; Kamitori, S.; Harada, A. J. Am. Chem.

Soc. 2005, 127, 2034

10 Shigekawa, H.; Miyake, K.; Sumaoka, J.; Harada, A.; Komiyama, M. J. Am. Chem. Soc. 2000, 122, 5411.

11 Miyake, K.; Yasuda, S.; Harada, A.; Sumaoka, J.; Komiyama, M.; Shigekawa, H. J. Am. Chem. Soc. 2003, 125, 5080.

${ }^{12}$ See, for example, (a) Rodriguez P.; Sanchez M.; Isasi J.R., González-Gaitano, G. Appl. Spectrosc. 2002, 56, 1490; (b) Sainz-Rozas, P.R.; Isasi, J.R., Sánchez, M.; Tardajos, G.; González-Gaitano, G. J. Phys. Chem. A. 2004, 108, 392.

13 Bax, A.; Davis, D. G. J. Magn. Reson. 1985, 63, 207.

${ }^{14}$ MesteRe-C. version 3.7.9; Departamento de Química Orgánica, Universidad de Santiago de Compostela: Santiago de Compostela, Spain, 2004.

${ }^{15}$ Neuhaus, D.; Williamsom, M. P. The Nuclear Overhauser Effect in Structural and Conformational Analysis, VCH: New York, 1989.

16 Ämmälahti, E.; Bardet, M.; Molko, D.; Cadet, J. J. Magn. Reson. A. 1996, 122, 230.

${ }^{17}$ Insight II, version 2000: Accelrys Inc.: San Diego, CA, 2000. 
${ }^{18}$ AutoDock 3.0.5.; G.M. Morris, D.S. Goodsell, R. Huey, W.E. Hart, S. Hilliday, R. Belew, A.J. Olson, "Automated docking of flexible ligands to receptors" (2001).

${ }^{19}$ Sainz-Rozas, P.R.; Isasi, J.R., González-Gaitano, G. J. Photochem. Photobiol. A: Chem. 2005, 173, 319.

${ }^{20}$ Connors. K.A. J. Pharm. Sci. 1995, 84, 843.

${ }^{21}$ Rekharsky, M.V.; Inoue, Y. Chem. Rev. 1998, 98, 1875.

${ }^{22}$ Funasaki, N.; Ishikawa, S.; Neya, S.; J. Phys. Chem. B. 2002, 106; 6431.

${ }^{23}$ Salvatierra, D.; Jaime, C.; Virgili, A.; Sánchez-Ferrando, F. J. Org. Chem. 1996, 61, 9578.

${ }^{24}$ Salvatierra, D.; Sánchez-Ruiz, X.; Garduño, R.; Cervelló, E.; Jaime, C.; Virgili, A.; Sánchez-Ferrando, F. Tetrahedron, 2000, 56, 3035.

${ }^{25}$ Zubiaur, M.; Jaime, C. J. Org. Chem. 2000, 65, 8139.

${ }^{26}$ González-Gaitano, G.; Sainz-Rozas, P.R.; Isasi, J.R.; Tardajos, G.; GuerreroMartínez, A. J. Phys. Chem. B. 2004, 108, 14154.

${ }^{27}$ Morris, G. M.; Goodsell, D.S.; Halliday, R.S.; Huey, R.; Hart, W.E.; Belew, R.K.; Olson, A.J. J. Comput. Chem. 1998, 19, 1640.

${ }^{28}$ Dodziuk, H (Ed.). "Modeling of CyDs and Their Complexes", in "Cyclodextrins and Their Complexes”, Wiley-VCH Verlag GmbH \& Co. KgaA, Weinheim, 2006. 

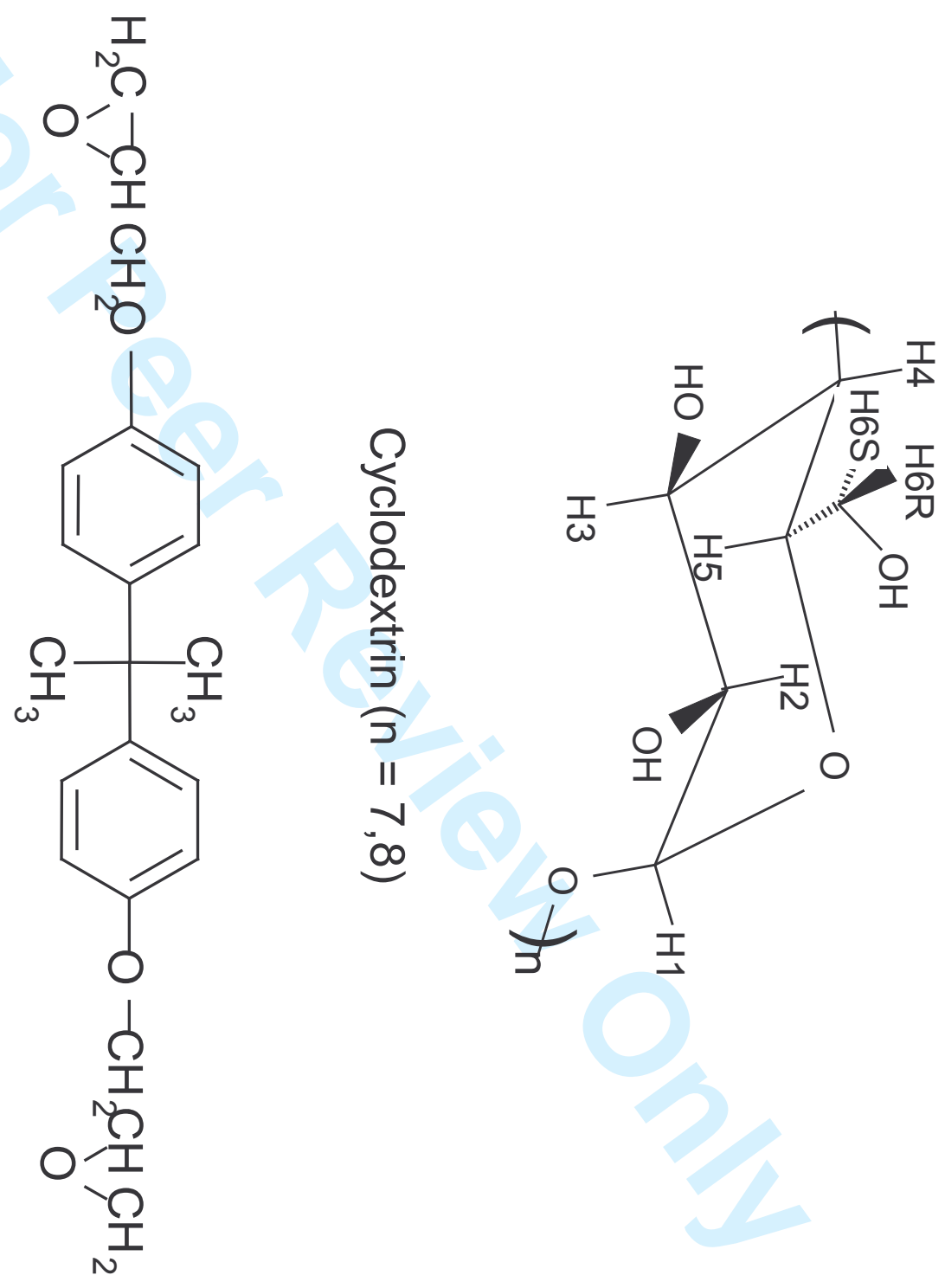

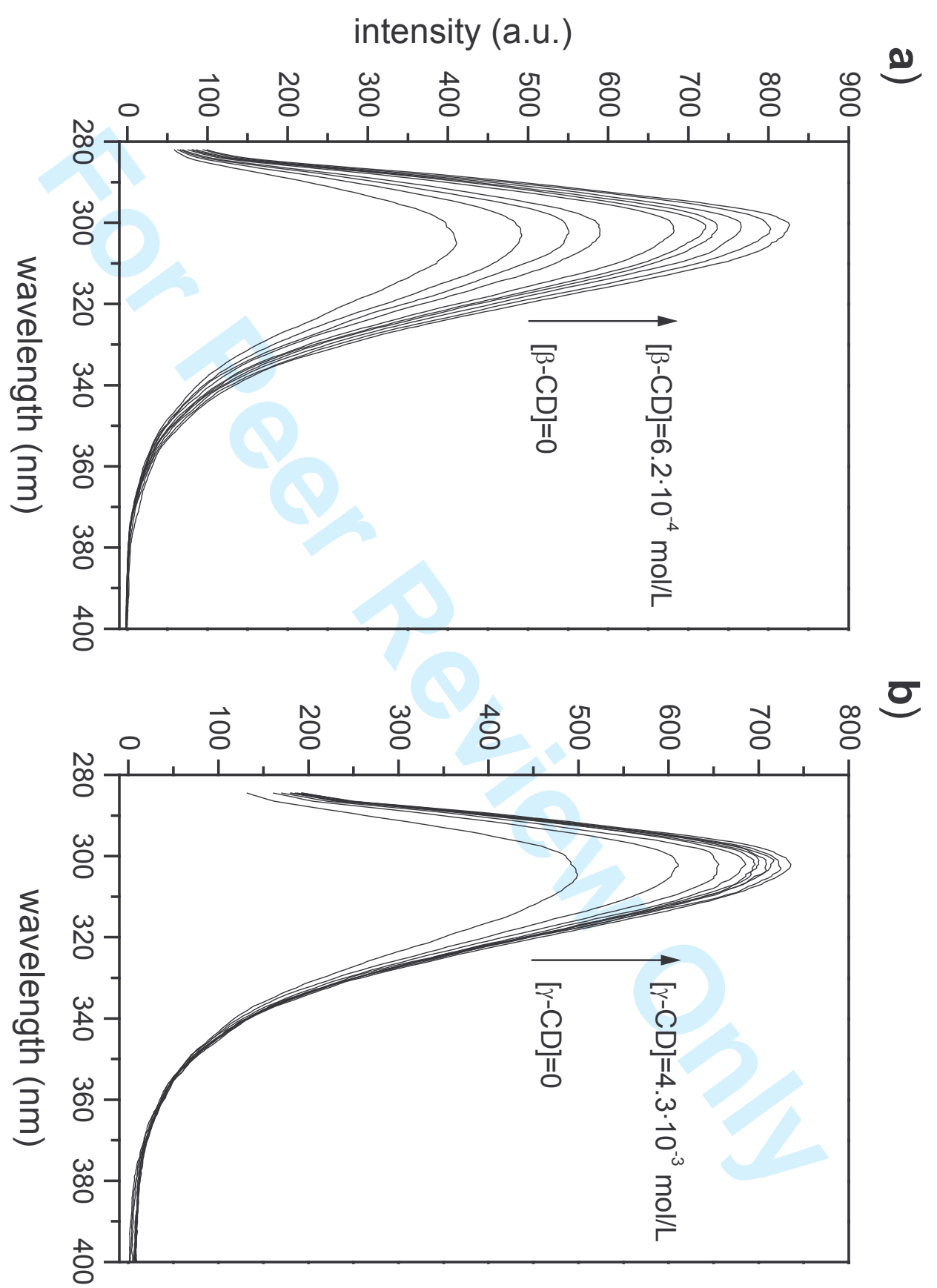

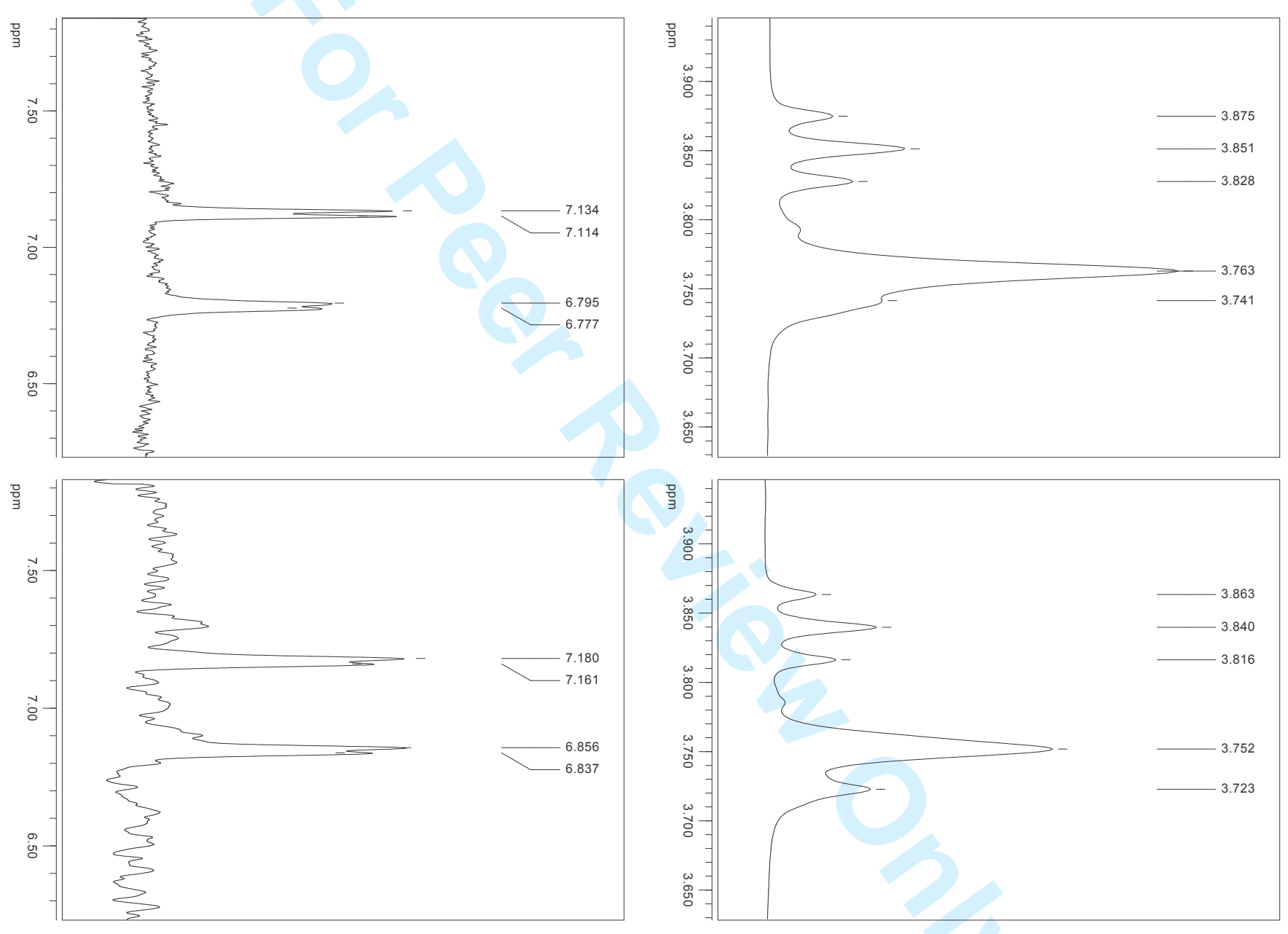


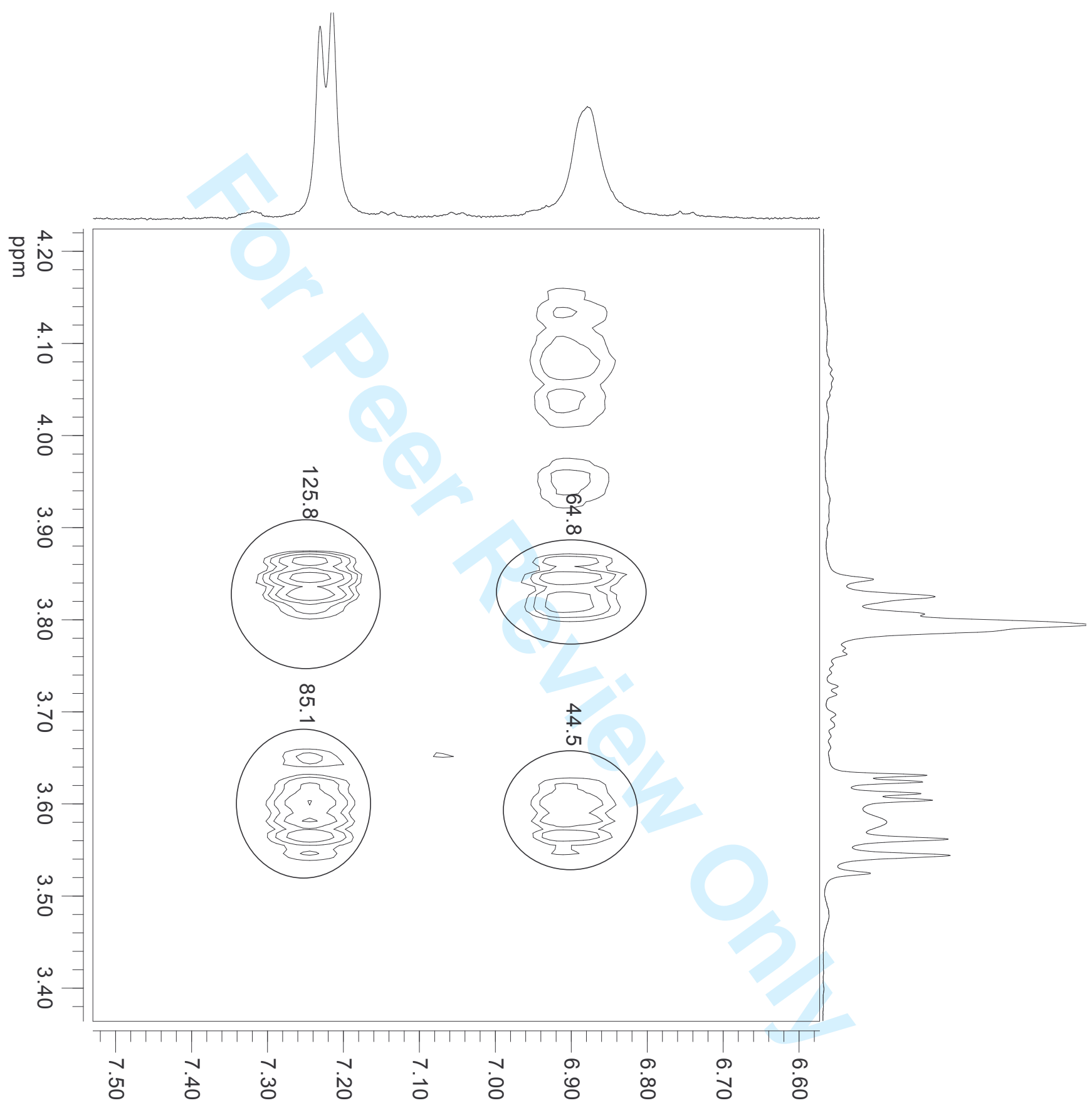




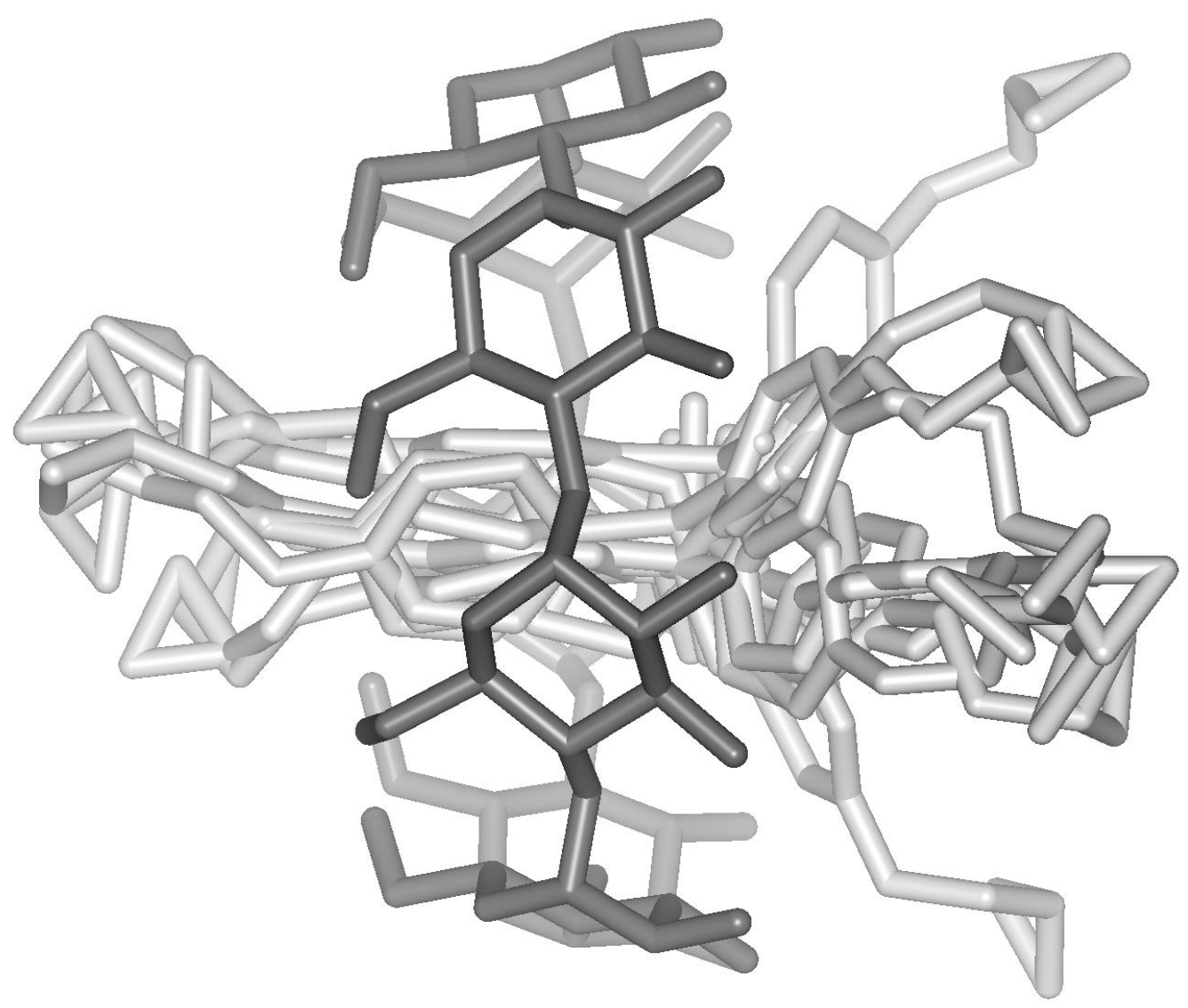




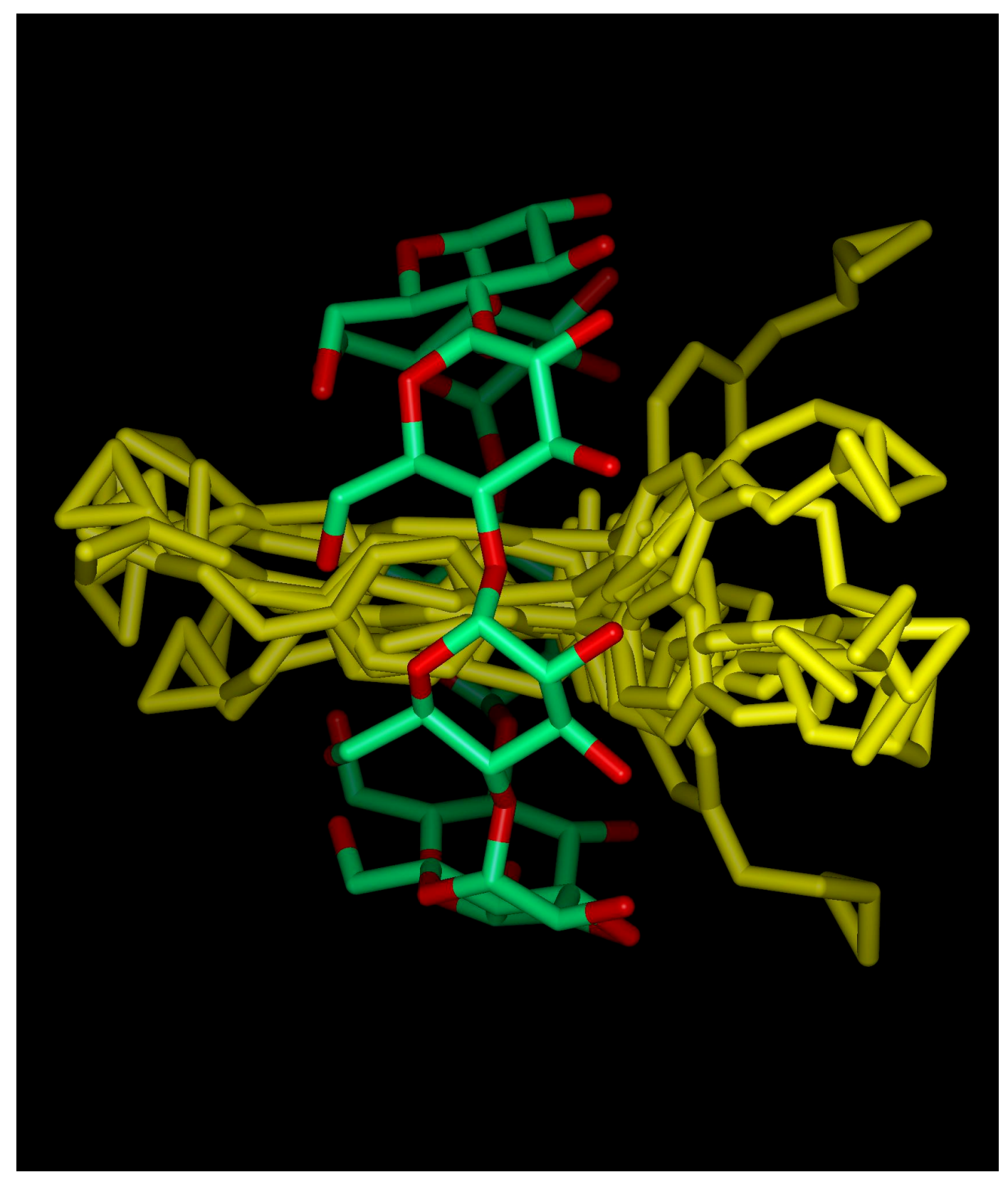


Figure 6

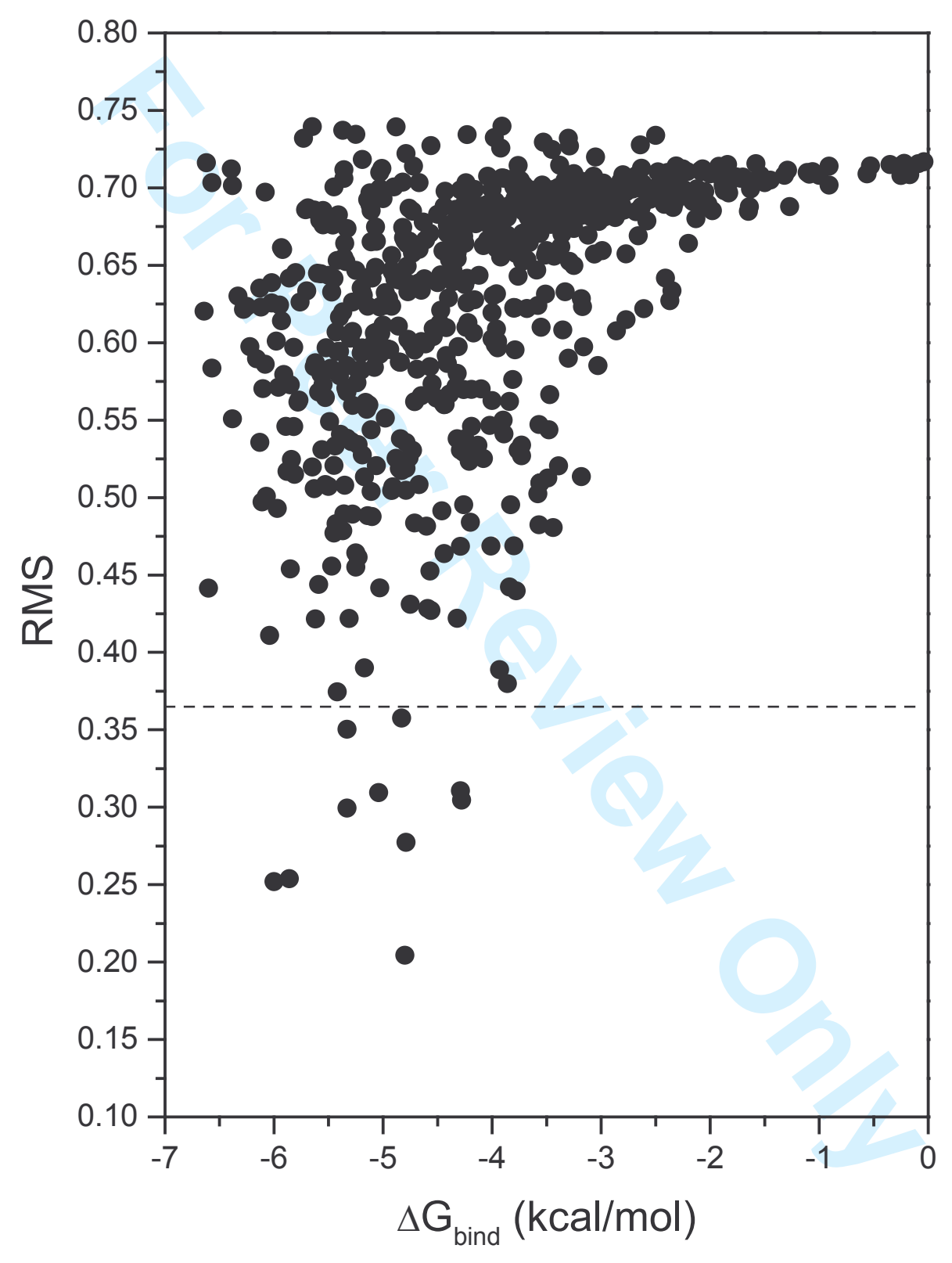

